\title{
Pyrethroid insecticide residue in 'Grande Naine’ banana peel and pulp during maturation
}

\author{
Ariane CASTRICINI ${ }^{1 *}$, Ana Luiza Santos de OLIVEIRA ${ }^{2}$, Gevany Paulino de PINHO ${ }^{2}$, \\ Maria Geralda Vilela RODRIGUES ${ }^{1}$, Flaviano Oliveira SILVÉRIO²
}

\begin{abstract}
In banana farming, the bagging of bunches with bags impregnated by pyrethroid insecticide is a practice that prevents damage to fruits caused by insect pests. The aim of this study was to monitor the presence and permanence of bifenthrin residue during the maturation of 'Grande Naine' banana by gas chromatography coupled to mass spectrometer in the selective ion mode (GC-MS-SIM). Fruits were from bagged and non-bagged bunches and the extraction of bifenthrin residue from peel and pulp was performed with QuEChERS and LSE-LTP (Liquid-Solid Extraction - Low Temperature Partitioning) methods. The maturation stages were characterized as $1 ; 3$ and 7 depending on the fruit peel color. The bifenthrin recovery percentages in banana peel and pulp obtained by QuEChERS and LSE-LTP methods are between $97 \%$ and $117 \%$, and therefore, within the criteria of acceptability for residues of agrochemicals according to the Brazilian legislation and vary according to the matrix. The mean bifenthrin concentrations in the peel of fruits from bagged bunches were $0.34 \mathrm{mg} \mathrm{kg}^{-1}, 0.29 \mathrm{mg} \mathrm{kg} \mathrm{and} 0.10 \mathrm{mg} \mathrm{kg}^{-1}$ at stage 1 (harvest point); 3 and 7, respectively. No bifenthrin residue was detected in fruit pulp at any maturation stage.
\end{abstract}

Keywords: Musa sp.; bunch packing; post-harvest; gas chromatography.

Practical Application: GC-MS analysis detected bifenthrin residue in banana during maturation stage.

\section{Introduction}

Southeastern Brazil is the third largest banana producing region in the country, with more than 2 million tons produced, and northern Minas Gerais occupies the fourth position in the national production, only behind the southern coast of São Paulo, southern state of Bahia and north state of Santa Catarina (Instituto Brasileiro de Geografia e Estatística, 2016). Banana 'Grande Naine' cultivar belongs to the Cavendish subgroup (AAA) and according to Gao et al. (2016), cultivars of this subgroup are widely cultivated, since they dominate the international fruit trade, being mainly consumed fresh or as dessert.

According to Singh et al. (2016), banana contains sufficient amount of bioactive compounds beneficial to health, such as antioxidants, even in the peel that is usually discarded. Although ripe and peeled pulp is the main part of the fruit to be consumed, green fruits with or without peel or only the green peel, are used for the elaboration of green banana flour (Bezerra et al., 2013; Silva et al., 2015), which can be used both by the food industry as an ingredient in the preparation of ready-made dishes and in the preparation of meat products (Silva et al., 2015).

The control of pests and diseases in banana farming, whether in the plant or in the fruit, is of fundamental importance for the quality of fruits during and after harvest. Bagging bunches with bags impregnated with insecticides is used to control pests. Bagging is done while the inflorescence is hanging and closed or when bunches are open (Rodrigues et al., 2015). Bifenthrin (pyrethroid insecticide) is used for the control of banana fruit rust (Caliothrips bicinctus) (Brasil, 2017).

According to Li et al. (2016), pyrethroid insecticides are widely used in agriculture, and they, as well as their degradation products, can remain as residue in foods like fruits and vegetables. Bifenthrin has toxicological classification IV (slightly toxic) and according to the National Agency of Sanitary Surveillance from Brazil, the Maximum Residue Limit (MRL) in banana is $0.02 \mathrm{mg} \mathrm{kg}^{-1}$, with a 1-day safety interval (Brasil, 2016a). However, in the case of bagging of bunches with bags impregnated with bifenthrin, the safety interval is not specified (Brasil, 2017). The Codex Alimentarius (Food and Agriculture Organization of the United Nations, 2014) establishes MRL at $0.1 \mathrm{mg} \mathrm{kg}^{-1}$. Li et al. (2016) found that bifenthrin and cypermethrin were the two most frequently detected pyrethroids in fruit and vegetable samples, accounting for about $69 \%$ of all residues studied. According to Heudorf \& Angerer (2001) and Schettgen et al. (2002), the exposure to pyrethroids by the population occurs mainly via residues present in food.

QuEChERS (Quick, Easy, Cheap, Effective, Rugged, Safe Method) and LSE-LTP (Liquid Solid Extraction - Low Temperature Partitioning) methods are used for the extraction of insecticides in foods samples. In this sense, Carneiro et al. 
(2013) quantified 128 pesticides in banana using the QuEChERS method for extraction, and Esquievel Hernández (2015), who also used LSE-LTP in the extraction stage of six agrochemicals and concluded that both extraction methods can be used for analysis of pesticide residues in both banana pulp and peel. The separation and identification of bifenthrin is performed by gas chromatography (GC) or high performance liquid chromatography (HPLC), according to results obtained by Marthe et al. (2010) and Savi et al. (2016).

From the harvesting time, when bananas are physiologically developed but not yet suitable for consumption until maturation, there may be residues of products used during the production period. However, due to the photodegradation, which is an important process of decomposition of pyrethroids such as bifenthrin (Tariq et al., 2017), the concentrations of these residues may decrease as time passes. The study of the permanence of pesticide residues until consumption, not only in the pulp of the fruit but also in its peel, is relevant under the perspective of food safety because, according to the European Food Safety Authority (2011), the ingestion of bifenthrin in foods may cause allergic reactions, dermatitis, asthma, bronchitis, nasal stuffiness and sneezing.

In this sense, the aim of this study was to monitor the presence and permanence of bifenthrin residue during maturation of 'Grande Naine’ banana by GC-MS-SIM.

\section{Materials and methods}

\subsection{Sample collection}

'Grande Naine' (AAA) banana samples belonging to the Cavendish group were grown in an experimental area in northern Minas Gerais (Brazil), located at the following geographical coordinates: $15^{\circ} 47^{\prime} 29^{\prime \prime} \mathrm{S}$ and $43^{\circ} 17^{\prime} 88^{\prime \prime} \mathrm{W}$, with average altitude of $500 \mathrm{~m}$ above sea level, average annual rainfall of $800 \mathrm{~mm}$, and climate classified as Aw (tropical savanna) according to Köppen.

Bags were used to wrap (bagging) bunches after appearance until the moment of harvest in order to control pests and protect fruits against sunburn. The bag used in the bagging is internally impregnated with bifenthrin pyrethroid insecticide $\left(1 \mathrm{~g} \mathrm{~kg}^{-1}\right)$. In the Laboratory of Agrochemical Research (LPA) of the Institute of Agrarian Sciences, Federal University of Minas Gerais, Montes Claros, MG, banana peel and pulp samples from bagged and non-bagged bunches were processed. Although it is likely that fruits from non-bagged bunches do not show bifenthrin residue, contact between the different bunches after harvesting may provide the incidence of residues. Analyses of bifenthrin residues in banana peel and pulp were carried out at three maturation stages: harvest point, which corresponds to stage 1 (Figure 1A) and during maturation (stages 3 and 7) (Figure 1B and C). Fruits at harvest point or at the point of commercial maturity presented maximum growth, were slightly bent, and with completely green peel, corresponding to stage 1 of the Loesecke scale, used by the Ceagesp Classification Standards (Companhia de Entrepostos e Armazéns Gerais de São Paulo, 2006). During maturation, the samples analyzed corresponded to fruits at stage 3 (more green than yellow) and stage 7 (yellow with brown areas), according to the Loesecke scale. Fruits remained in the LPA at room temperature $\left(25 \pm 2{ }^{\circ} \mathrm{C}\right)$ for seven and thirteen days after harvest, where they reached maturation stages 3 and 7 , respectively.

The peel color at each maturation stage (Table 1) was measured by Minolta Colorimeter, model Chroma meter CR 400, L C H system. The colorimeter expresses color using three parameters: (a) luminosity $\left(\mathrm{L}^{*}\right)$, which varies from 0 (black) to 100 (white); (b) chromaticity or color purity $\left(C^{\star}\right)$, whose relatively lower values represent impure colors (grayish), and higher values, more intense colors, and (c) hue or true color angle ( ${ }^{\circ} \mathrm{Hue}$ ) ranging from $0^{\circ}$ to $360^{\circ}$, where angle $0^{\circ}$ corresponds to red color, $90^{\circ}$ to yellow color, $180^{\circ}$ or $-90^{\circ}$ to green color, $270^{\circ}$ or $-180^{\circ}$ to blue color, and goes from red to black in $360^{\circ}$.

Table 1. Color of the 'Grande Naine' banana peel at each maturation stage, measured by luminosity $\left(\mathrm{L}^{*}\right)$, chroma $\left(\mathrm{C}^{*}\right)$ and color angle (Hue).

\begin{tabular}{cccc}
\hline \multicolumn{4}{c}{ Maturation stage } \\
\hline Peel color & 1 & 3 & 7 \\
\hline $\mathrm{L}^{*}$ & 58.68 & 66.23 & 65.30 \\
$\mathrm{C}^{\star}$ & 43.69 & 43.11 & 45.70 \\
Hue angle & 119.32 & 112.10 & 97.97 \\
\hline
\end{tabular}

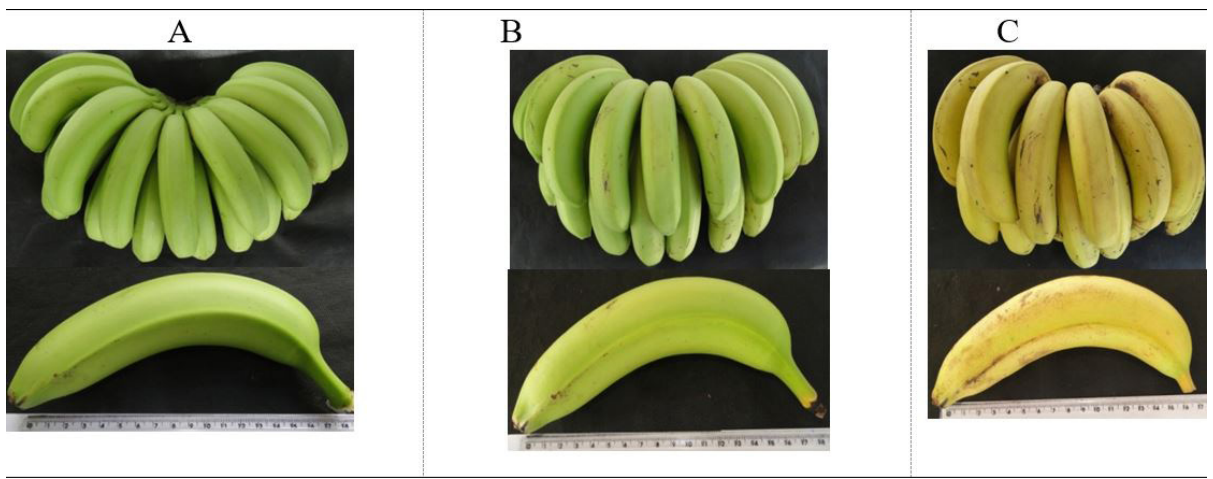

Figure 1. Banana 'Grande Naine’ cultivar at harvest point - stage 1 (A) and during maturation at stages 3 (B) and 7 (C). Fotos: Ariane Castricini. 


\subsection{Sample preparation}

'Grande Naine' banana peel and pulp samples were homogenized; peel was chopped with a knife and the pulp macerated in pestle and mortar. After homogenization, bifenthrin was extracted using the modified QuEChERS method (Carneiro et al., 2013) and by liquid-solid extraction with low temperature partitioning (ESL-PBT), according to Esquievel Hernández (2015).

For extraction of bifenthrin by QuEChERS, a total of $10 \mathrm{~g}$ of sample was weighed into a polypropylene centrifuge tube $(50 \mathrm{~mL})$ and then $10 \mathrm{~mL}$ of acidified acetonitrile was added with $1 \%(\mathrm{v} / \mathrm{v})$ acetic acid. Vortexing was carried out for $1 \mathrm{~min}$.; then $4.0 \mathrm{~g}$ of anhydrous magnesium sulfate and $1.0 \mathrm{~g}$ of sodium acetate were added, with subsequent vortexing for $1 \mathrm{~min}$. The system was centrifuged at $4000 \mathrm{rpm}$ for $9 \mathrm{~min}$ and then $2 \mathrm{~mL}$ of the supernatant was transferred to a $15 \mathrm{~mL}$ Falcon tube containing $1.5 \mathrm{~g}$ of anhydrous magnesium sulfate. The system was vortexed again for 1 minute and centrifuged ( $4000 \mathrm{rpm}$ ) for $9 \mathrm{~min}$. Finally, $1 \mathrm{~mL}$ of the supernatant was transferred to the injection vial and, subsequently, $1 \mu \mathrm{L}$ was injected into the gas chromatograph.

For the extraction of bifenthrin by LSE-LTP from banana peel and pulp, $2.0 \mathrm{~g}$ of minced and macerated sample, respectively, were weighed and added in glass flasks with capacity of $22.0 \mathrm{~mL}$ with screw cap. Flasks containing peel samples were added of $1.50 \mathrm{~mL}$ of ultrapure water, $3.25 \mathrm{~mL}$ of acetonitrile and $0.75 \mathrm{~mL}$ of ethyl acetate. For extraction in pulp samples, the amounts of water, acetonitrile and ethyl acetate were $0.50 \mathrm{~mL}, 3.25 \mathrm{~mL}$ and $0.75 \mathrm{~mL}$ respectively. Then, both peel and pulp mixtures were vortexed for $1 \mathrm{~min}$ and then centrifuged for $5 \mathrm{~min}$ at $2500 \mathrm{rpm}$ and cooled to $-18^{\circ} \mathrm{C}$ for $3 \mathrm{~h}$.

After the freezing time, the lower aqueous phase, frozen with pulp or peel, was separated from the upper liquid phase, containing the organic solvent and the extracted analyte. Samples were prepared in duplicate.

\subsection{Chromatographic analyses}

Reagents - Standard stock bifenthrin solutions (92.2\% w / w) - FMC do Brasil, were prepared in acetonitrile at concentration of $500.0 \mathrm{mg} \mathrm{L}^{-1}$ and stored at $4{ }^{\circ} \mathrm{C}$. From the stock solutions, a working solution containing $50 \mathrm{mg} \mathrm{L}^{-1}$ pyrethroid was prepared. HPLC grade acetonitrile (Vetec, Rio de Janeiro, Brazil), sodium acetate and magnesium sulphate with purity grade higher than 99\% ( $\mathrm{m} / \mathrm{m}$ ) were used as solvent, also purchased from Vetec (Rio de Janeiro, Brazil).

\subsection{Sample fortification}

Bananas produced in northern state of Minas Gerais coming from crop without pesticides were used. Peel and pulp samples were processed as described in item 'sample preparation' and fortified with bifenthrin in the concentration of $50 \mathrm{ppb}$ for later extraction by LSE-LTP and QuEChERS. For fortification and extraction by QuEChERS and LSE-LTP, flasks containing $10.0 \mathrm{~g}$ and $2.0 \mathrm{~g}$ of peel or pulp, respectively, were allowed to stand for $3 \mathrm{~h}$ to allow interaction of bifenthrin with the matrix and solvent evaporation.

\subsection{Chromatographic equipment and conditions}

Phoenix Vortex (São Paulo, Brazil); Kindly centrifuge (São Paulo, Brazil); Ethik Technology greenhouse (São Paulo, Brazil) and Shimadzu analytical scale (São Paulo, Brazil) were used for sample preparation.

Gas chromatograph from Agilent Technologies (GC 7890A) coupled to a mass detector (MS 5975C) was used. DB-5 MS (Agilent Technologies) capillary column was used with 5\% diphenyl and 95\% dimethylpolysiloxane as stationary phase $(30 \mathrm{~m}$ in length $\times 0.32 \mathrm{~mm}$ in internal diameter $\times 0.25 \mu \mathrm{m}$ in internal film thickness). The oven temperature was programmed to start at $150{ }^{\circ} \mathrm{C}(1 \mathrm{~min})$, then at heating rate of $15^{\circ} \mathrm{C} \mathrm{min}-1$ to $220^{\circ} \mathrm{C}$, remaining at this temperature for 1 minute and then heating rate of $30{ }^{\circ} \mathrm{C} \mathrm{min}-1$ to $290{ }^{\circ} \mathrm{C}$, remaining at this temperature for 4 minutes. The analysis showed total time of 14 minutes. Helium (99.9999\% purity) was used as the carrier gas at rate of $1 \mathrm{~mL} \mathrm{~min}^{-1}$. The split/splitless injector temperature was maintained at $280^{\circ} \mathrm{C}$. The volume of sample injected was $1 \mu \mathrm{L}$ in the injection mode without flow division (splitless), using Combi PAL auto injector. The mass spectrometer was operated in electron impact ionization mode at $70 \mathrm{eV}$. The interface was maintained at $300{ }^{\circ} \mathrm{C}$ and the source of ions at $230{ }^{\circ} \mathrm{C}$. Instrument control and data acquisition were performed with ChemStation software (E.02.02.1431 copyright $^{\odot}$ 1989-2011) from Agilent Technology. Analyses were performed in the selective ion monitoring mode (SIM). The ions selected for analysis were 303.9; 305.9 and $307.9 \mathrm{~m} / \mathrm{z}$.

A completely randomized design with two replicates for fruit peel and pulp from bagged or non-bagged bunches was used at each maturation stage. The replicates 1 and 2 were composed of 5 fruits of the first and second bunch, of the each banana bunches, respectively. A $3 \times 2$ factorial analysis of variance (ANOVA) was performed, with maturation stages (3) and extraction methods (2) being the causes of variation. Both ANOVA and the Tukey test were performed in the SAEG 9.1 software (Universidade Federal de Viçosa, 2007).

\section{Results and discussion}

The chromatogram of standard bifenthrin solution at $1 \mathrm{mg} \mathrm{L}^{-1}$ concentration is shown in Figure 2, where it is found that the retention time was 9.44 minutes.

After extraction, the bifenthrin recovery percentages in banana pulp and peel in both extraction methods are presented in Table 2. For banana peel, QuEChERS and LSE-LTP provided higher recovery percentages. The LSE-LTP method extracted 99.69\% from the pulp and for QuEChERS method, the recovery percentage was $96.72 \%$. According to criteria of acceptability for pesticide residues stipulated by the Analytical Quality Assurance Manual (Brasil, 2011), the analytical procedure must be capable of recovering, at each fortification level and for each representative matrix, from $70 \%$ to $120 \%$ on average for all analytes. In this sense, it was verified that the recovery percentage by QuEChERS and LSE-LTP in both banana peel and pulp is within the established standards. However, in both methods, peel recovery was higher than $100 \%$, probably due to the matrix effect that, according to Lehotay \& Eller (1995) and Yamazaki 


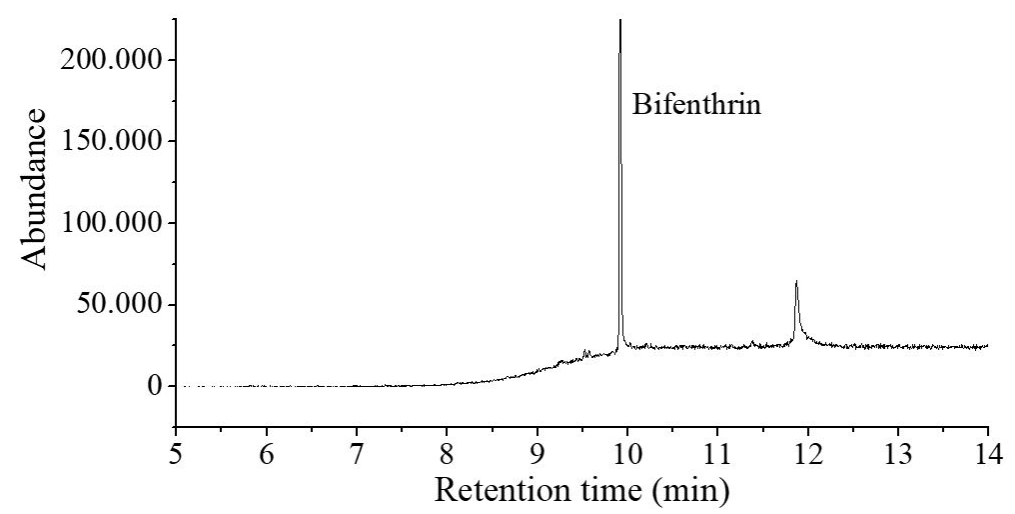

Figure 2. Chromatogram of the standard bifenthrin solution at $1 \mathrm{mg} \mathrm{L}^{-1}$.

Table 2. Recovery percentages (\% R) of bifenthrin in 'Grande Naine' banana peel and pulp.

\begin{tabular}{cccccc}
\hline \multirow{2}{*}{ Matrix } & \multicolumn{2}{c}{ QuEChERS } & & \multicolumn{2}{c}{ LSE-LTP } \\
\cline { 2 - 3 } \cline { 5 - 6 } & Work range $(\mathrm{ppb})$ & Recovery $\% \pm$ RSD & & Work range (ppb) & Recovery \% \pm RSD \\
Peel & 50 to 500 & $111 \pm 2$ & & 25 to 500 & $117 \pm 6$ \\
Pulp & 50 to 500 & & $25 \pm 4$ to 500 & $100 \pm 3$ \\
\hline
\end{tabular}

RSD = Relative Standard Deviation; QuEChERS = Quick, Easy, Cheap, Effective, Rugged, Safe Method; LSE-LTP = Liquid Solid Extraction - Low Temperature Partitioning.

\& Ninomiya (1996) is more pronounced in analyses of complex samples, such as those of fruits. In this sense, Sousa et al. (2012) evaluated the matrix effect in the analysis of 11 agrochemicals and found that tomato, grape and pineapple matrixes caused greater matrix effect, but apple and potato samples caused a small matrix effect in evaluations.

The matrix effect is used to explain the recovery rates of pesticides that exceed $100 \%$ and the low accuracy of results (Hajslová et al., 1998).

There was no significant interaction between maturation stages and extraction methods for the bifenthrin residue found in the study samples, thus, isolated effect of factors occurred (Table 3).

The chromatograms of 'Grande Naine' banana peel and pulp extracts from bunches bagged with bifenthrin-impregnated bags are shown in Figure 3. Bifenthrin insecticide was detected only in the fruit peel (Figure 3A and C) with significant reduction of concentration at maturation stage 7 (Table 4A). This trend was observed for both LSE-LTP and QuEChERS extraction methods (Figure $3 \mathrm{~A}$ and $\mathrm{C}$ ), with the highest mean concentration (Table 4B) attributed to the latter. In the pulp, the presence of bifenthrin, regardless of maturation stage (Figure 3B and D), was not detected, probably due to the physical protection that the peel confers and the anatomy of the fruit, according to Cutter (2002) the peel separates from the pulp in the region of the parenchyma as conspicuous air spaces that expand considerably.

Bifenthrin is a synthetic pyrethroid insecticide and according to Tariq et al. (2017), several factors influence the degradation of pyrethroids in the environment, such as soil and molecule type, climate, size and species of soil microbial population. Additionally, photodegradation is also an important process in the decomposition of these pesticides. The authors verified
Table 3. Summary of the analysis of variance for bifenthrin residue in 'Grande Naine' banana peel during maturation and as a function of the extraction method.

\begin{tabular}{ccc}
\hline S.V. & D.F & Mean Square \\
\hline Maturation stage (MS) & 2 & $0.15^{*}$ \\
Extraction method (EM) & 1 & $0.16^{*}$ \\
MS ${ }^{*}$ EM & 2 & $0.10^{\text {ns }}$ \\
Residue & 7 & \\
VC (\%) & & 17.21 \\
\hline
\end{tabular}

S.V. = Sources of variation; D.F = Degrees of freedom; MS = Maturation stage; $\mathrm{EM}=$ Extraction method; ${ }^{\mathrm{ns}}=$ not significant; ${ }^{\star}$ Significant at $5 \%$ by the $\mathrm{F}$ test.

rapid degradation of bifenthrin when under UV irradiation. According to Santos et al. (2007) sensitivity to light varies among the different types of pyrethroids, with bifenthrin and fenpropatrin showing low sensitivity to this factor.

Although there was a reduction in bifenthrin concentration during maturation at maturation stage 7 , which is generally when the fruit is consumed, there was still $0.10 \mathrm{mg} \mathrm{kg}^{-1}$ of bifenthrin in banana peel samples. It is worth mentioning that this value is higher than $0.02 \mathrm{mg} \mathrm{kg}^{-1}$, which is the MRL provided for in the Brazilian legislation for this pesticide. However, the residue was only detected in the peel, that is, inedible part of the fruit, but can be consumed when used in the manufacture of green banana flour, with culinary use. In addition, at the time of manual peeling of the fruit, for consumption, there may be pulp contamination with residue present in the peel. According to Donkor et al. (2016), the presence of pesticide residues in food products is a source of great concern, mainly because some fruits 
A

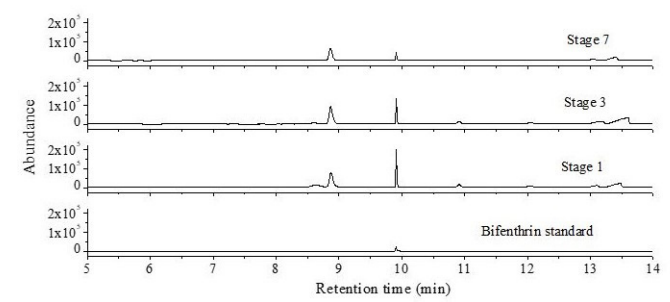

B

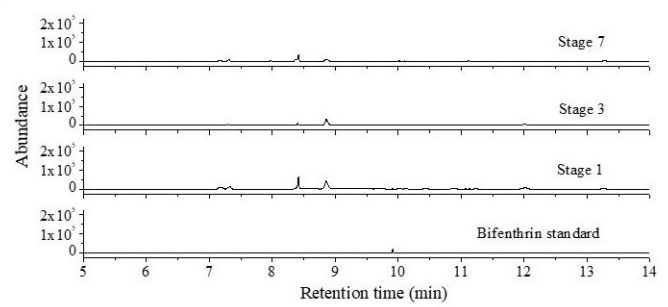

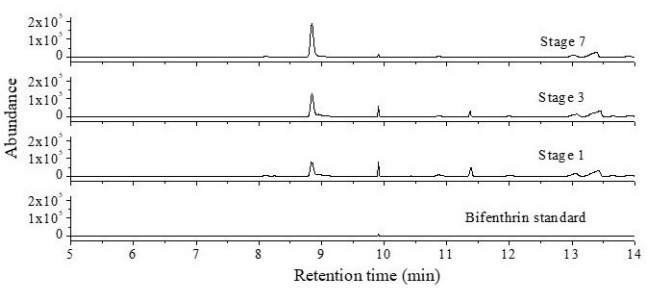

$\mathrm{D}$

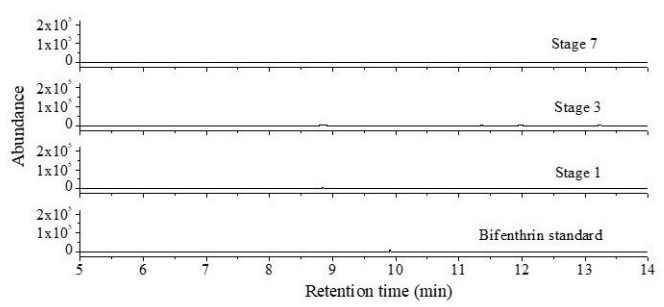

Figure 3. Chromatogram of 'Grande Naine' banana peel and pulp extracts. Bifenthrin extracted by QuEChERS in peel (A) and pulp (B) and by LSE-LTP in peel (C) and pulp (D) of 'Grande Naine' banana during maturation.

Table 4. Bifenthrin residue in 'Grande Naine' banana peel during maturation (A) and as a function of the extraction method (B).

\begin{tabular}{lccc}
\hline & \multicolumn{3}{c}{ A) Maturation stage } \\
\hline Bifenthrin $\left(\mathrm{mg} \mathrm{kg}^{-1}\right)$ & 1 & 3 & 7 \\
& $0.34 \mathrm{~A}$ & $0.29 \mathrm{~A}$ & $0.10 \mathrm{~B}$ \\
Bifenthrin $\left(\mathrm{mg} \mathrm{kg}^{-1}\right)$ & QuEChERS & B) Extraction method \\
& $0.28 \mathrm{~A}$ & LSE-LTP \\
\hline
\end{tabular}

and vegetables are consumed fresh or semi-processed and may contain high levels of chemicals.

In contrast, the Report of the Program for Analysis of Agrochemical Residues in Foods of ANVISA (Brasil, 2016b) reported the presence of bifenthrin residues and other agrochemicals in bananas, with concentrations above MRL. However, in laboratory analyses in the context of PARA, the food as a whole and not only its edible parts is analyzed.

\section{Conclusions}

The bifenthrin recovery percentages in banana peel and pulp obtained by QuEChERS and LSE-LTP methods are between $97 \%$ and $117 \%$, and therefore, within the criteria of acceptability for residues of agrochemicals according to the Brazilian legislation and vary according to the matrix. The mean bifenthrin concentrations in the peel of fruits from bagged bunches were $0.34 \mathrm{mg} \mathrm{kg}^{-1}$, $0.29 \mathrm{mg} \mathrm{kg}^{-1}$ and $0.10 \mathrm{mg} \mathrm{kg}^{-1}$ at stage 1 (harvest point); 3 and 7 , respectively. No bifenthrin residue was detected in fruit pulp at any maturation stage.

\section{Acknowledgements}

To FAPEMIG for granting a postdoctoral fellowship to the first author. To CNPq for the grant of productivity grant (process 307381/2015-3) to the fifth author.

\section{References}

Bezerra, C. V., Rodrigues, A. M., Amante, E. R., \& Silva, L. H. M. (2013). Nutritional potential of green banana flour obtained by drying in spouted bed. Revista Brasileira de Fruticultura, 35(4), 1140-1146. http://dx.doi.org/10.1590/S0100-29452013000400025.

Brasil, Agência Nacional de Vigilância Sanitária - ANVISA. (2016a, May 27). Consulta pública $n^{\circ} 168$, de 25 de maio de 2016. Diário Oficial [da] República Federativa do Brasil. Retrieved from http:// portal.anvisa.gov.br/documents/10181/2777507/CONSULTA+P\% C3\%9ABLICA+N+168+GGTOX+2016.pdf/509c32a1-d365-43329e34-4086027597ab

Brasil, Agência Nacional de Vigilância Sanitária - ANVISA. (2016b). Programa de Análise de Resíduos de Agrotóxicos em Alimentos (PARA): relatório das análises de amostras monitoradas no período de 2013 a 2015. Brasília: ANVISA. Retrieved from http://portal.anvisa.gov. br/documents/111215/0/Relat\%C3\%B3rio+PARA+20132015

VERS\%C3\%83O-FINAL.pdf/494cd7c5-5408-4e6a-b0e5-5098cbf759f8

Brasil, Ministério da Agricultura Pecuária e Abastecimento. (2011). Manual de garantia da qualidade analítica. Brasília: MAPA/ACS. Retrieved from www.agricultura.gov.br>laboratórios

Brasil, Ministério da Agricultura Pecuária e Abastecimento. (2017). Agrofit: sistema de agrotóxicos fitossanitários. Brasília. Retrieved from http:// agrofit.agricultura.gov.br/agrofit_cons/!ap_produto_form_detalhe_ cons?p_id_produto_formulado_tecnico=8195\&p_tipo_janela $=\mathrm{NEW}$

Carneiro, R., Oliveira, F. A. S., Madureira, F. D., Silva, G., de Souza, W. R., \& Lopes, R. P. (2013). Development and method validation for determination of 128 pesticides in bananas by modified QuEChERS and UHPLC MS/MS analysis. Food Control, 33(2), 413-423. http:// dx.doi.org/10.1016/j.foodcont.2013.02.027.

Companhia de Entrepostos e Armazéns Gerais de São Paulo - CEAGESP. Programa Brasileiro para a Modernização da Horticultura \& Produção Integrada de Frutas - PBMH-PIF. (2006). Normas de classificação de banana (Documentos, Vol. 29). São Paulo: CEAGESP.

Cutter, E. G. (2002). Anatomia vegetal: células e tecidos (2. ed., Vol. 2). São Paulo: Roca.

Donkor, A., Osei-Fosu, P., Dubey, B., Kingsford-Adaboh, R., Ziwu, C., \& Asante, I. (2016). Pesticide residues in fruits and vegetables in Ghana: a review. Environmental Science and Pollution Research 
International, 23(19), 18966-18987. http://dx.doi.org/10.1007/ s11356-016-7317-6. PMid:27530198.

Esquievel Hernández, A. L. A. (2015). Comparação de métodos multirresíduos para determinação de produtos fitossanitários em polpa e casca de banana (Dissertação de mestrado). Universidade Federal de Viçosa, Viçosa.

European Food Safety Authority - EFSA. (2011). Conclusion on the peer review of the pesticide risk assessment of the active substance bifenthrin. European Food Safety Authority Journal, 9, 2159.

Food and Agriculture Organization of the United Nations - FAO. (2014). Codex Alimentarius: normas internacionais dos alimentos. Rome: FAO. Retrieved from http://www.codexalimentarius.org/ about-codex/es/

Gao, H., Huang, S., Dong, T., Yang, Q., \& Yi, G. (2016). Analysis of resistant starch degradation in postharvest ripening of two banana cultivars: focus on starch structure and amylases. Postharvest Biology and Technology, 119, 1-8. http://dx.doi.org/10.1016/j. postharvbio.2016.03.022.

Hajslová, J., Holadova, K., Kocourek, V., Poustka, J., Godula, M., Cuhra, P., \& Kempny, M. (1998). Matrix-induced effects: a critical point in the gas chromatographic analysis of pesticide residues. Journal of Chromatography. A, 800(2), 283-295. http://dx.doi.org/10.1016/ S0021-9673(97)01145-X. PMid:9474786.

Heudorf, U., \& Angerer, J. (2001). Metabolites of pyrethroid insecticides in urine specimens: current exposure in an urban population in Germany. Environmental Health Perspectives, 109(3), 213-217. http:// dx.doi.org/10.1289/ehp.01109213. PMid:11333180.

Instituto Brasileiro de Geografia e Estatística - IBGE. (2016). SIDRA: produção agrícola municipal. Rio de Janeiro: IBGE. Retrieved from https://sidra.ibge.gov.br/Tabela/1613 29/01/2018

Lehotay, S. J., \& Eller, K. I. (1995). Development of a method of analysis for 46 pesticides in fruits and vegetables by supercritical fluid extraction and gas chromatography/ion trap mass spectrometry. Journal of AOAC International, 78(3), 821-830. PMid:7756898.

Li, W., Morgan, M. K., Graham, S. E., \& Starr, J. M. (2016). Measurement of pyrethroids and their environmental degradation products in fresh fruits and vegetables using a modification of the quick easy cheap effective rugged safe (QuEChERS) method. Talanta, 151, 42-50. http://dx.doi.org/10.1016/j.talanta.2016.01.009. PMid:26946008.
Marthe, D. B., Bittencourt, L. M., Queiroz, M. E. L. R., \& Neves, A. A. (2010). Desenvolvimento de metodologia para determinação de piretroides em manteiga. Química Nova, 33(6), 1389-1393. http:// dx.doi.org/10.1590/S0100-40422010000600030.

Rodrigues, M. G. V., Donato, S. L. R., Lichtemberg, L., \& Dias, M. S. C. (2015). Implantação e condução do bananal. Cultivo da Bananeira. Informe Agropecuário, 36(288), 27-44.

Santos, M. A. T., Areas, M. A., \& Reyes, F. G. R. (2007). Piretróides: uma visão geral. Alimentos e Nutrição, 18(3), 339-349.

Savi, G. D., Piacentini, K. C., Bortolotto, T., \& Scussel, V. M. (2016). Degradation of bifenthrin and pirimiphos-methyl residues in stored wheat grains (Triticum aestivum L.) by ozonation. Food Chemistry, 203, 246-251. http://dx.doi.org/10.1016/j.foodchem.2016.02.069. PMid:26948611.

Schettgen, T., Heudorf, U., Drexler, H., \& Angerer, J. (2002). Pyrethroid exposure of the general population: is this due to diet. Toxicology Letters, 134(1-3), 141-145. http://dx.doi.org/10.1016/S03784274(02)00183-2. PMid:12191872.

Silva, A. A., Barbosa, J. L. Jr., \& Barbosa, M. I. M. J. (2015). Farinha de banana verde como ingrediente funcional em produtos alimentícios. Ciência Rural, 45(12), 2252-2258. http://dx.doi.org/10.1590/01038478cr20140332.

Singh, B., Singh, J. P., Kaur, A., \& Singh, N. (2016). Bioactive compounds in banana and their associated health benefits: a review. Food Chemistry, 206, 1-11. http://dx.doi.org/10.1016/j.foodchem.2016.03.033. PMid:27041291.

Sousa, F. A., Costa, A. I. G., Queiroz, M. E. L. R., Teófilo, R. F., Neves, A. A., \& Pinho, G. P. (2012). Evaluation of matrix effect on the GC response of eleven pesticides by PCA. Food Chemistry, 135(1), 179185. http://dx.doi.org/10.1016/j.foodchem.2012.04.063.

Tariq, S. R., Ahmed, D., Farooq, A., Rasheed, S., \& Mansoor, M. (2017). Photodegradation of bifenthrin and deltamethrin: effect of copper amendment and solvent system. Environmental Monitoring and Assessment, 189(2), 71-79. http://dx.doi.org/10.1007/s10661-0175789-6. PMid:28116604.

Universidade Federal de Viçosa - UFV. (2007). SAEG: sistema para análises estatísticas, versão 9.1. Viçosa: UFV.

Yamazaki, Y., \& Ninomiya, T. (1996). Determination of imazalil residues in lemons by gas chromatography with nitrogen-phosphorus detection. Journal of AOAC International, 79(3), 787-790. PMid:8634546. 